\title{
TRADUÇÃO \\ Crítica da ideologia como crítica das práticas sociais: uma reconstrução expressivista da crítica da falsa consciência'
}

\author{
Titus Stahl²
}

O par de conceitos "ideologia" e "crítica da ideologia" teve uma carreira impressionante. 0 conceito de ideologia, em especial, fluiu para o nosso vocabulário cotidiano e hoje parece ser de compreensão geral como nenhum outro elemento do arcabouço conceitual marxista - e não apenas na esteira da crítica da ideologia marxista e de inspiração marxista. ${ }^{3}$ No entanto, essa carreira anda de mãos dadas com uma rejeição generalizada do conceito de "ideologia": para além de sua função evocativa, defende-se amplamente que o conceito não é capaz de cumprir propósito crítico ou explicativo algum por se basear em uma distinção entre falsa consciência e consciência verdadeira que não pode mais ser considerada plausível. ${ }^{4}$

No que se segue, eu gostaria de mostrar que essa crítica - assim como muitas objeções populares à teoria marxiana da ideologia - se apoia em uma ambivalência nas numerosas e nem sempre sistematicamente contextualizadas observações sobre a ideologia que encontramos em Marx (Leist, 1987, p. 61; Rosen, 1996, p. 222). De um lado, Marx adota uma representação cotidiana da "falsa consciência" que implica em uma concepção "cognitivista" da falsidade das ideologias e que, portanto, identifica como ideologia determinados fenômenos intelectuais em razão de sua inverdade

1 Stahl, T. (2013). Ideologiekritik als Kritik sozialer Praktiken. Eine expressivistische Rekonstruktion der Kritik falschen Bewusstseins. In: Jaeggi, R, \& Loick, D. (orgs.), Nach Marx: Philosophie, Kritik, Praxis (pp. 228-254). Berlin: Suhrkamp. Tradução de Rafael Zanvettor, mestrando em filosofia pela Universidade de São Paulo (USP) e bolsista da Fundação de Amparo à Pesquisa do Estado de São Paulo (FAPESP) - Processo No 2018/07118-0.

2 Professor de filosofia da Universidade de Groningen e autor de Immanente Kritik: Elemente einer Theorie sozialer Praktiken. Frankfurt am Main: Campus Verlag, 2013.

3 Como demonstra o corpus do "Google Books", o uso do adjetivo "ideológico" ultrapassou o adjetivo "anticientífico" nos anos 20, e aparece de dez a quinze vezes mais em livros de meados dos anos 60. Apesar da tendência de queda, hoje sua frequência ainda se encontra nos patamares de 1968. Recuperado de: Google Ngram Viewer: ideologisch, unwissenschaftlich, <http://books. google.com/ngrams/graph? content=ideologisch\%2C+unwissenschaftlich\&year_start=1900\&year_ end=2000\&corpus=8\&smoothing 3>, último acesso: 30.05.2012.

4 Os representantes mais conhecidos desta tese são Foucault (1978, p. 34) e Rorty (1993; 1992) mas o ceticismo associado a ideologia é generalizado. Cf. a este respeito: Rosen (1996) e Leist (1987, p. 77). Para um resumo sobre o tema: Rehmann (2008, p. 13).

$5 \mathrm{Na}$ ausência de um conceito melhor, tomo essa palavra da metaética. Embora a analogia não seja totalmente correta, deve apenas apontar que o que está no centro desta análise é a verdade das afirmações. 
ou falha epistemológica (I). Por outro lado, encontramos na crítica de Marx aos jovens hegelianos abundantes objeções ao entendimento da ideologia como simples equívoco, ou seja, objeções a colocar em primeiro plano a história epistemológica ou valor de verdade das ideologias (II). Pelo contrário, a inovação da teoria da ideologia de Marx consiste precisamente em apresentar uma abordagem alternativa que, em lugar de uma crítica epistêmica, traz ao centro uma análise materialista das formas das ideias sociais (III). É exatamente por meio desta inovação, no entanto, que Marx se depara com o dilema de que a teoria da ideologia resultante põe em xeque a aplicabilidade dos critérios epistêmicos que a tornava plausível como crítica (IV) - o que frequentemente levou teorias modernas da ideologia a renunciarem a ideia de uma crítica (normativa) da ideologia em favor de uma teoria da ideologia "meramente" científica. Porém, ao abandonarmos a suposição cientificista de que as práticas materiais escapam dos fundamentos da argumentação da crítica cognitiva, somos capazes de desenvolver uma concepção de práticas sociais que eu gostaria de chamar de "expressivista" (V): as práticas sociais podem institucionalizar distinções que tanto podem assumir formas ideológicas como não ideológicas. Podemos, a partir disso, entender a crítica da ideologia como uma crítica das práticas sociais. Essa determinação da crítica da ideologia, concluímos, pode também acolher a intuição cognitivista de que ideologias são inverdades $(\mathrm{VI})$, resolvendo o aparente dilema entre crítica da ideologia e teoria da ideologia.

\section{Crítica da ideologia como crítica cognitivista}

A crítica da ideologia não é um fim em si mesmo. Criticamos ideologias porque partimos do princípio de que a sociedade seria melhor se as pessoas não fossem impedidas de certas ações pela ideologia e se motivassem a agir de outro modo. Segundo o uso cotidiano do conceito, “ideologias" são sistemas de fenômenos intelectuais que acreditamos serem responsáveis pela falta de liberdade, sofrimento, dominação ilegítima ou outras patologias (Geuss, 1983; Jaeggi, 2009). Mas mesmo o conceito vulgar de ideologia indica algo mais específico do que a totalidade dos fenômenos intelectuais que consideramos responsáveis pela manutenção de injustiças sociais. 0 medo justificado de um ditador brutal pode, por exemplo, impedir a libertação de sua dominação, mas ele não é falso enquanto medo e, portanto, não é ideologia (Geuss, 1983, p 25; Eagleton, 2000, p.68). Apenas aqueles fenômenos intelectuais cujas más consequências são imputáveis aos seus próprios defeitos enquanto fenômenos intelectuais podem ser ideologias. Esse é especialmente o caso quando se baseiam em falsas crenças, desejos infundados, projeções ilusórias ou coisas do gênero.

Embora o conceito de ideologia de Marx tenha um conteúdo mais complexo e não se refira apenas a crenças falsas que tenham consequências sociais negativas, 
o fato de que as ideologias são cognitivamente deficitárias ainda desempenha um papel importante. A falsidade da ideologia é para Marx também uma falsidade de pensamento. ${ }^{6}$ Nas passagens em que ele utiliza o conceito de ideologia não apenas de modo descritivo, mas crítico, ele quer dizer que a ideologia se reporta a uma relação intelectual com o mundo, em si inadequada por não preencher determinados padrões de justificabilidade - na Ideologia Alemã, por exemplo, ele fala em termos de "fantasias inocentes e infantis" (1958, p. 13/523), "7 "ilusões" (idem, 18/527) e enganos. 0 propósito político da crítica da ideologia (que se reflete até hoje no uso cotidiano da palavra) é sempre, acima de tudo, criticar pensamentos, teorias, programas e ideais de atores políticos por serem falsos, ilusórios, injustificados ou inconsistentes - um fato que fala em favor da compreensão da ideologia como falsidade de pensamento. Entretanto, tal ideia de crítica deve entender a ideologia como uma falsa consciência que está em oposição, em certo sentido, a uma possível consciência correta. Essa determinação tem consequências imediatas para a crítica: se quisermos criticar crenças que têm consequências sociais negativas em razão de sua falsidade, não podemos nos apoiar apenas na condenação das consequências dessas crenças. Obviamente, não é uma questão sem importância se uma patologia social é gerada por crenças corretas ou falsas: enquanto no primeiro caso podemos criticar os fatos a que se referem essas crenças (o seu truthmaker ${ }^{8}$ ) ou os mecanismos que conectam as crenças a suas consequências negativas, apenas no segundo caso encontramos uma crítica das próprias crenças, ou seja, uma crítica da ideologia de fato. Qualquer conceito de ideologia que caracterize a falsidade da ideologia como falsidade cognitiva deve, portanto, na crítica da ideologia, apoiar-se também nessa falsidade cognitiva (Jaeggi, 2009, p.268).

Eu gostaria de denominar isso de intuição cognitivista (C) da crítica cotidiana da ideologia:

(C): A crítica da ideologia é uma crítica das falhas cognitivas em fenômenos intelectuais (isto é, nas relações intelectuais dos indivíduos com a realidade).

6 Nas palavras de Marco lorio: “Como prova disso nos remetemos, por exemplo, para o prefácio da Ideologia Alemã, que deixa suficientemente claro que os ideólogos são, aos olhos de Marx e Engels, loucos mal orientados filosoficamente ou apologetas de visões arcaicas" (2003, p. 93); sobre o uso epistêmico em geral ver Geuss (1983, p. 23).

7 N. T.: Por ser a principal fonte de referência para o autor deste artigo e para facilitar o cotejo do leitor em português, todas a citações d'A ideologia alemã serão realizadas com duas paginações. A primeira, após a data, se refere ao original em alemão. A segunda refere-se à tradução brasileira: Marx, K. \& Engels, F. (2007). A ideologia alemã. São Paulo: Boitempo. As outras citações de Marx terão como referência no corpo do texto apenas a edição original.

$8 \mathrm{~N}$. do T.: Não há consenso entre os tradutores do conceito para o português, alguns se referem a ele como "fazedor de verdade", outros como "veridador". Segui a opção do autor e mantive a palavra original, em inglês. 
Ainda que essa intuição, sem dúvida, encontre expressão frequente em Marx, quase não há passagens em que sua crítica seja baseada na falsidade de qualquer tipo de crença tão somente. Em vez disso, Marx e Engels adotam, especialmente a partir da crítica dos jovens hegelianos à religião na Ideologia Alemã, uma importante distinção entre o conteúdo das crenças (ideias, aspirações) e a autocompreensão epistêmica que as sustenta: os jovens hegelianos criticam as ilusões religiosas não apenas por serem falsas em um sentido banal, mas, acima de tudo, porque os atores religiosos compreendem mal a si mesmos quando acreditam que se apoiam no conhecimento de um Deus, quando na realidade desenvolvem crenças a partir de suas próprias qualidades humanas. Aqui se trata sempre, portanto, de uma crítica a crenças de segunda ordem, ou seja, crenças sobre o status de outras crenças.

Para complicar as coisas, Marx e Engels passam então a utilizar tal crítica, isto é, a crítica à autocompreensão de suas crenças, contra os próprios jovens hegelianos (Schnädelbach, 1969): na Ideologia Alemã, Marx e Engels tem em mente a crítica da ideologia dos jovens hegelianos como um caso paradigmático do ideológico porque, segundo sua visão, eles mesmos são guiados por crenças falsas sobre crenças ao realizar a crítica da ideologia. A análise de crenças religiosas, tomadas como crenças que se fundam em uma autoincompreensão, pressupõe, segundo Marx e Engels, a premissa de que podemos compreender as ideologias religiosas apenas com base em suas propriedades cognitivas (a saber, como resultado de um processo de projeção epistemologicamente duvidoso) (Marx \& Engels, 1958, p. 19/256; Elster, 1985). Assim, os jovens hegelianos têm uma crença sobre as crenças de indivíduos religiosos: "crenças religiosas são o resultado de uma projeção”. Esta crença, no entanto, implica uma teoria geral de todas as crenças: "crenças só podem ser explicadas por suas propriedades cognitivas e sua história epistêmica". Em particular, eles acham que os erros cognitivos explicam não apenas as crenças religiosas, mas também um estado de abusos históricos e políticos, e que, portanto, sua crítica cognitiva é necessária e significativa para mudar a realidade política (Eagleton, 2000, 87): “Aqui, como em geral ocorre com os ideólogos, é de se notar que eles necessariamente colocam a questão de cabeça para baixo e veem na sua ideologia tanto a força motriz como o objetivo de todas as relações sociais, enquanto ela é tão somente sua expressão e seu sintoma" (Marx \& Engels, 1958, p. 405/405).

É isso que Marx e Engels tomam por falso - no sentido normal da palavra (Leist, 1987, p. 63). As crenças dos jovens hegelianos formam assim um caso exemplar do ideológico porque se baseiam em falsas crenças sobre o status, o papel social e o funcionamento do intelecto, ou seja, em falsas crenças de segunda ordem (Rosen, 1996, p.33; Geuss, 1983, p. 23). E com a estrutura do intelecto que passa a ser entendida deste modo, não apenas as crenças singulares, mas toda a estrutura torna-se ideológica. Uma vez que a crítica a crenças falsas de segunda ordem é apresentada na 
Ideologia Alemã como o projeto central da crítica da ideologia, a crítica da ideologia não parece criticar quaisquer crenças por sua falsidade mas critica, em primeiro lugar, a falsa compreensão das atitudes intelectuais, as falsas orientações em nossas crenças ou uma falsa estrutura reflexiva de nossa relação cognitiva com o mundo.

\section{Crítica da ideologia como crítica não-epistêmica}

Essa afirmação ainda não representa um problema para o modelo de uma crítica da ideologia cognitiva apresentado até o momento: Marx e Engels parecem continuar a lidar com uma crítica de crenças falsas, exceto pelo que parecem limitar o escopo de sua crítica às ideias. Entretanto, o que se demonstra com facilidade é que esta leitura cognitivista de crítica é posta em xeque pelos argumentos colocados por ela mesma contra os jovens hegelianos, que acreditavam que as operações intelectuais podem ser entendidas desvinculadas de seus fundamentos materiais, ou seja, que elas podem ser apresentadas a princípio como autossuficientes. Marx e Engels defendem a tese de que apenas entendemos as crenças em seu sentido ideológico quando percebemos que elas são parte da realidade material histórico-social. Portanto, temos que entender que a verdade das crenças ideológicas e sua justificação epistêmica não são os únicos fatores que devemos utilizar para explicar o porquê de sua existência. A fim de apreender verdadeiramente de que modo as ideologias são falsas ideologicamente, precisamos dirigir o olhar para seu papel em eventos históricos não intelectuais. Tal explicação seria, de acordo com Marx e Engels, uma teoria que compreende o intelectual como "emanação" [Ausfluß] (1958, p. 26/93) do comportamento "material" - isto é, de práticas humanas mediadas intelectual, social e historicamente. Assim, as ideologias só podem ser adequadamente compreendidas no contexto de tais processos, o que significa dizer que sua falsidade cognitiva só pode ser entendida em referência a tais processos.

Eu chamaria isso de perspectiva materialista9:

(M): A falsidade das ideologias só pode ser entendida no contexto de seu papel na realidade histórico-social.

Desta tese, portanto, advêm uma consequência de forte lógica de convencimento que Marx e Engels estavam também preparados para delinear: se todas as ideias só podem ser apreendidas no contexto das relações materiais (Elster, 1985, p. 475), também só se pode apreender o erro de segunda ordem cometido pelos jovens hegelianos - a saber, o erro de apreender ideias como fatores autônomos - no contexto das relações materiais, ou, como diz Marx, das "formas de intercâmbio"

\footnotetext{
9 "Materialista" significa aqui, assim como na Ideologia Alemã de Marx e Engels, não necessariamente "relacionada à matéria", mas no tocante às formas sociais de organização da interação humana com a natureza (Schnädelbach, 1969, p. 81; Rosen, 1996, p. 182).
} 
[Verkehrsformen] (1958, 168/184). Isso significa, em especial, que elas devem ser conceituadas como o que "emana" da divisão entre trabalho manual e trabalho intelectual (Rehmann, 2008, p. 30; Hindrichs, 2010). Assim, a crítica da ideologia dos jovens hegelianos não é ideológica apenas por ser falsa, mas porque expressa determinadas relações sócio-históricas de um determinado modo. ${ }^{10}$ Se esse é o caso, uma crítica a essa teoria da ideologia que se detivesse apenas em sua falsidade, falta de fundamentação ou premissas problemáticas, estaria destinada ao erro. Tal crítica iria pressupor no nível da teoria o que teria de negar ao nível do objeto: a ideia de que processos intelectuais, pelo menos de modo ideais, devem ser conduzidos e esclarecidos exclusivamente por meio de critérios cognitivos. Se rejeitamos isso como crença ideológica, não podemos tomar como motivo desta rejeição o fato de que esta crença não é em si mesma suficientemente guiada por critérios cognitivos.

Ao generalizamos o argumento, revela-se o dilema em que a crítica da ideologia segundo o modelo de Marx se enrosca: se a falsidade das ideologias só pode ser concebida a partir de seu papel em prática sociais, então a intuição que motiva a crítica "cotidiana" da ideologia, ou seja, a intuição de uma crítica sobretudo cognitiva, parece estar equivocada. Pois ainda que o conteúdo de uma ideologia possa ser verdadeiro ou falso, isso ainda não esclarece em qual sentido o papel que é desempenhado por esse conteúdo na práxis o torna um conteúdo ideológico. Dito de outro modo, a teoria da ideologia materialista de Marx parece ter a tendência de colocar em xeque sua crítica da ideologia cognitivista. ${ }^{11}$

\section{Crítica da ideologia como crítica da sociedade}

A relação entre $(M)$ e $(C)$ é complexa: $(M)$ apresenta apenas, de início, a perspectiva de um aspecto necessário para uma teoria explicativa da ideologia, enquanto que $(C)$ define as normas de uma crítica valorativa da ideologia. Se, no entanto, aceitamos que a crítica a uma crença é equivocada quando essa crença é criticada pela falta de critérios que orientem o processo de sua fundamentação, vêse então que a crítica puramente cognitiva deve permanece puramente externa. ${ }^{12}$ Ou seja, não podemos formular uma crítica apropriada da ideologia com base em (C) e, mais do que isso, a crítica da ideologia deve ser uma crítica direcionada não à natureza cognitiva mas, em primeiro lugar, à natureza material da estrutura das

10 Assim diz Schnädelbach: "o intelecto autonomizado (...) deve ser considerado, portanto, como um fato social" $(1969$, p. 80$)$.

11 Como diz Eagleton, por exemplo: "a teoria que identifica essa falsidade retira com um só golpe sua própria fundamentação, porque denuncia uma situação que ela, como teoria, não pode mudar “. (2000, p. 87)

12 Na crítica da filosofia do direito de Hegel: “Isso é, ainda, crítica dogmática, que luta contra seu objeto (...). A verdadeira crítica, em vez disso, mostra a gênese interna da Santíssima Trindade no cérebro humano." (Marx, 1976, p. 296). [Trad. Bras.: Marx, K. (2010) Crítica da filosofia do direito de Hegel. São Paulo: Boitempo, p. 108]. 
relações cognitivas com o mundo.

Naturalmente, tudo depende do que significa exatamente dizer que a estrutura das ideologias tem uma "natureza material". Marx e Engels concretizaram isso em uma conhecida passagem, segundo a qual os "pensamentos dominantes" devem ser entendidos como expressão das relações materiais de dominação. (Marx \& Engels, 1958, p. 46/47). As formulações mais conhecidas dessa ideia de expressão assumem que ela nos remete quer a uma origem causal problemática [kausal mangelhafte Herkunft], ou seja, a uma determinação social original das ideias, quer à explicação das ideologias através de sua funcionalidade em determinadas ordens de dominação (Cohen, 2000, pp. 278-293; Geuss, 1983, pp. 24-29). O critério da origem causal problemática sugere descrever como ideológico todo aquele fenômeno intelectual cuja origem social não permite ser reconhecida reflexivamente como admissível (Geuss, 1983, pp. 29-31). Por outro lado, o critério da funcionalidade identifica como ideológico todo fenômeno intelectual que é funcional para uma ordem de dominação (injusta ou desnecessária), ou seja, que é funcionalmente necessário para a continuidade da existência de tal ordem de dominação ou que se esclarece por meio de sua função para tal ordem de dominação.

As duas propostas têm diversos problemas, que acabam por desqualificá-las. Em primeiro lugar, não há um modo convincente de diferenciar a origem social ilegítima da legítima. O critério da admissibilidade reflexiva apenas desloca a questão: ou se quer dizer com isso que algo se revela ideológico apenas se sua história de origem não pudesse ou não fosse aceita por ninguém em circunstâncias "ideais", ou, por outro lado, significa que esse algo não devesse ser aceito racionalmente. Tanto a caracterização das "circunstâncias ideais" quanto a ideia de uma "admissibilidade racional" já pressuporiam, no entanto, uma definição do ideológico (Geuss, 1983; Rosen, 1996). Por outro lado, os critérios funcionais, se não se reportam à um modelo de explicação funcional, se mostram ou demasiado amplos (a princípio toda ideia pode ser funcional para uma ordem de dominação) ou demasiado restritos (nem toda ideologia é funcionalmente insubstituível). Não há, no entanto, um modelo plausível de tal explicação à vista (Elster, 1985; 1994; Cohen, 2000; Rosen, 1996). Além de tudo, não fica claro qual a correlação entre funcionalidade e falsidade.

Contudo, a objeção mais importante a ambas soluções é que ambas assumem ainda que a materialidade das ideologias está em contradição com sua aceitabilidade cognitiva, que o caráter material (i.e. funcional ou causal) de uma ideologia compromete as propriedades epistêmicas "realmente" relevantes. Dito de outro modo: mesmo estas propostas continuam a aderir à ideia de que a relação imaterial com o mundo, puramente cognitiva, deve ser realmente decisiva. Mas é essa ideia mesma que é criticada por Marx como ilusão especificamente ideológica. Para levar sua crítica a sério, é preciso encontrar uma maneira de interpretar a tese da materialidade de modo que todo o pensamento, seja ideológico ou não, esteja 
descrito materialmente na interpretação. O problema é que, com isso, a possibilidade de uma crítica da ideologia cognitivista parece se tornar obscura e - enquanto não for desenvolvido um processo de crítica da ideologia não-cognitivista - o projeto da crítica como um todo se encontra em perigo.

Marx, no entanto, não apenas opõe aos jovens hegelianos as teses da incorporação do material ao intelectual de modo abstrato, mas contrasta a crítica da ideologia ingênua com a crítica social materialista. Isso supõe que as ideologias não são falsas de modo independente, mas são a expressão bem-sucedida e apropriada de relações falsas. A afirmação de que as ideologias não dizem respeito a uma expressão defeituosa, mas a uma expressão bem sucedida, é evidenciada pela metáfora da camera obscura: “Se, em toda ideologia, os homens e suas relações aparecem de cabeça para baixo como numa câmara escura, este fenômeno resulta do seu processo histórico de vida, da mesma forma como a inversão dos objetos na retina resulta do processo de vida imediatamente físico" (Marx \& Engels, 1958, p. 26/94).

A menção à função invertida do processo da vida revela que as ideologias, em certo sentido, expressam adequadamente efeitos de estados objetivamente deficitários. Elas não são autonomamente falsas, mas o são em razão da falsidade não cognitiva da realidade, que é responsável por esse caráter de falsidade. ${ }^{13}$

Daí resulta a seguinte pormenorização da aqui nomeada perspectiva materialista $(M)$ :

(M'): A crítica da ideologia critica a relação cognitiva ideológica dos indivíduos com a realidade social não porque a ideologia reproduz cognitivamente essa realidade de modo falso, mas porque assume que a ideologia é a expressão adequada de uma falsa realidade.

Já de início, novamente uma interpretação simples dessa tese se oferece: pode-se considerar que ideologias são crenças falsas que surgem porque a realidade social é enganosa, ou seja, porque tem uma tendência a causar falsas crenças nas pessoas (Rosen, 1996, p. 49; Schnädelbach, 1969, p. 83). Essa ideia é também apoiada por algumas passagens das obras de Marx: em 0 Capital ele descreve, no capítulo sobre o caráter fetichista da mercadoria no capitalismo, o modo pelo qual o valor da mercadoria aparece como se fosse sua própria qualidade quando, na realidade, é uma relação social (Marx, 1962, pp. 85-98). Mesmo alguém que não cometa um erro epistemológico pode, assim, ser presa dessa aparência; sua convicção é falsa, mas, do ponto de vista epistemológico, impecável.

No entanto, não está claro, em primeiro lugar, se uma realidade social que tem a tendência a causar falsas crenças em certas circunstâncias (circunstâncias

13 Aí afirma Habermas: "na reprodução correta do falsamente existente, a ideologia encontra seu limite mais extremo" (1963, p. 315) 
normais?) ainda poderia ser considerada "falsa" em sentido cognitivista, caso não realizasse essa tendência, ou seja, caso não fizesse surgir crenças falsas. Segundo o próprio testemunho de Marx, para continuar com mesmo exemplo citado acima, a própria economia política descobre já a essência do valor mas, no entanto, esse conhecimento não "elimina de modo algum a sua aparência objetiva” (Marx, 1963, p. 88; Rosen, 1996, p. 207). Mas seriam as circunstâncias desta situação, em que elas não enganam ninguém, ainda ideológicas? Caso sim, de que modo? Em segundo lugar, esse modelo introduz novamente, de modo furtivo, a verdade das crenças como critério para a falsidade das ideologias - e com isso introduz também ideia da autorregulação autônoma das ideias negada por Marx. Em terceiro lugar, por fim, esse modelo limita a relação de expressão entre a realidade e a ideologia a uma conexão puramente causal. Como expressão de uma realidade enganosa valem assim apenas aqueles (e todos aqueles) pensamentos que foram causados por essa realidade. Com isso a teoria da ideologia se compromete com uma explicação causal, a qual não se tem certeza de como poderia ser fundamentada empiricamente.

A alternativa a essas leituras proto-cognitivistas da falsidade da ideologia consiste em criticar a realidade não em face das crenças que causa, mas como realidade falsa em si mesma. Mas parece então que a crítica cognitivista finalmente se torna impossível. Um juízo sore a realidade social, não intelectual, independente do conhecimento humano não nos parece dar a possibilidade de determinar essa realidade como falsa ou irracional em sentido cognitivo. 0 projeto da crítica da ideologia parece, portanto, se tornar inconsistente assim que entende a si mesmo como crítica social materialista.

\section{O dilema da crítica da ideologia}

Em resumo: no dilema da crítica da ideologia temos de lidar com duas determinações que chamei, de um lado, de determinação cognitivista e, de outro, de perspectiva materialista. A determinação cognitivista é dependente da perspectiva materialista e, ao mesmo tempo, conflitante com ela. Ela é independente porque sem o conceito de uma realidade falsa fica nebuloso como se diferenciam as ideologias de outras crenças falsas. E é conflitante porque, ao assumir o caráter material da ideologia, põe em xeque sua própria crítica. Esse dilema sugere que a tese materialista só pode ser salvaguardada ao se abdicar da intuição cognitivista, ou seja, a ideologia pode ser explicada e descrita como forma de dominação materialmente mediada, mas não criticada em termos da substancialidade dos critérios cognitivos. ${ }^{14}$ Se seguimos essa sugestão, no entanto, a crítica da ideologia perde a conexão que a

14 Comparar este desenvolvimento de Althusser em Resch, por exemplo (1992, p.165); ver também a premissa anti-normativa baseada em Althusser em Therborn (1980, 5); por fim, Eagleton (2000, p. 29). 
liga ao conceito cotidiano de ideologia, e com ele, perde-se também grande parte da atratividade política do conceito de Marx.

O conflito entre ambas determinações, no entanto, só existe se a materialidade da ideologia é entendida de modo que as práticas materiais não possam ser objeto da crítica cognitivista e, assim, o discurso sobre a realidade material da qual as ideologias fazem parte, deve ser compreendido de tal modo cientificista que as relações de justificação e a ideia de verdade não podem cumprir nele papel algum. No entanto, esse cientificismo que motiva a substituição da crítica da ideologia pela teoria da ideologia não é de modo algum sem alternativa.

\section{Um conceito prático-teórico da ideologia}

Para desenvolver uma alternativa à leitura cientificista da tese da incorporação das ideologias na realidade material, precisamos desenvolver um entendimento expressivista, não causal, da afirmação que as ideologias são expressão das relações materiais. O conceito "expressivismo" remete a uma ideia filosófica cujo significado para a filosofia alemã do Séc. XIX. foi investigado por Charles Taylor: ${ }^{15}$ a ideia que uma determinada forma (seja uma forma de vida individual ou coletiva) se externa em expressões intelectuais e linguísticas e que, ao mesmo tempo, essas expressões esclarecem a essência de sua forma. ${ }^{16}$ Uma tal concepção de externalizações intelectuais e linguísticas se opõe à tese de que se tratam de fenômenos que podem ser suficientemente compreendidos apenas por meio de seu papel causal ou funcional. Eles devem ser compreendidos muito mais como realização de algo que não surge deles, mas que de outro modo não poderia ser compreendido sem essa realização mesma.

Essa ideia não é apenas vaga - especialmente nessa abstração-, mas também parece, à primeira vista, não ter muito a ver com Marx. Apesar disso, podemos aproximá-la do significado marxista se retomarmos a tese repetidamente acentuada por ele de que ideologias não tem a ver primordialmente com o conteúdo, mas com a forma dos pensamentos ${ }^{17}$ - expressão da "forma da sociedade" ou das "formas de

15 Contra Althusser, sou inteiramente da opinião que a metodologia expressivista da filosofia do Hegel resulta em uma leitura atraente de algumas afirmações de Marx se se mantiver a ideia básica de expressão, apesar de Marx ter se desligado da ideia de uma totalidade conceitualmente reconstituível (“o espírito"). Cf. Althusser, 1972, pp. 250-254). Para um argumento relacionado ver Rosen (1996, p. 208).

16 Esta complexa compreensão da relação expressiva também representa uma alternativa atraente para as teorias de argumentação causal: Se entendemos "determinação" não de modo causal, mas como determinação de uma expressão, torna-se claro que esta expressão por um lado não pode ser autônoma, caso contrário não seria uma expressão de algo, mas, ao mesmo tempo pode determinar e mudar o que é expresso - porque a expressão de uma prática social é (frequentemente) parte desta própria prática (Taylor, 1998, p.31; 1975, p.156).

$17 \mathrm{Em}$ contraste com o que assume lorio (2003, p. 91), por exemplo, pode-se certamente conferir sentido para esta conversa sobre "formas de pensamento": não se trata do conteúdo ou áreas temáticas, mas sim de formas. 0 religioso é ambos: um certo campo de conteúdos, mas também uma forma de pensamento. 
intercâmbio". Trata-se, portanto, de uma relação expressiva entre práxis e forma de pensamento. ${ }^{18}$

A “emergência” [Hervorgehen] da inversão ideológica a partir do "processo da vida" [Lebensprozess], que Marx e Engels postulam na passagem da "camera obscura" citada pode ser entendida também como expressão: a ideologia, ou seja, a falsa forma intelectual de sua autocompreensão, é falsa porque o "processo histórico de vida"[historische Lebensprozess] o é, isto é, a práxis na qual os homens regem sua vida social é igual e exatamente falsa do mesmo modo que a forma intelectual.

Mas o que significa dizer que pensamento e práticas podem ser falsos exatamente do mesmo modo? Para compreender essa afirmação, precisamos esclarecer de antemão o que é enfim o processo histórico de vida e as formas de troca, ou, em resumo, a práxis social de uma sociedade e sua forma. Eu entendo como uma prática social um conjunto de ações humanas estruturadas internamente por meio de padrões normativos de correção (Taylor, 1975; Stahl, p. 211). Em toda práxis deve haver distinções constitutivas [konstitutive Unterscheidungen] entre ações corretas e erradas - constitutivo aqui significa que essas diferenças constituem a prática enquanto prática. As distinções que as pessoas realizam nunca estão dadas de antemão na forma de uma tipologia natural, mas são socialmente institucionalizadas. Dizer que são "socialmente institucionalizadas" significa dizer que as pessoas só podem fazer distinções semelhantes, e de modo compreensível, porque antes de tudo há uma prática social que só existe se cada indivíduo fixar suas normas de modo substancial, determinado e não arbitrário. Isso só pode significar que há normas reguladas socialmente $e$ que quando os indivíduos adquirem a capacidade de estruturar dispositivamente seu próprio comportamento face essas normas através do processo de socialização - eles normalmente chegam aos mesmos juízos valorativos. Dito de outro modo: distinções práticas são apenas concebíveis sob a dupla exigência do aprendizado da capacidade de distinção ("habitus") e padrões socialmente regulados.

Tais distinções não precisam de modo algum serem encontradas em expressões discursivas das práticas. No entanto, em quase todas as práticas complexas elas se encontram de facto expressas em um vocabulário que podemos qualificar, com

18 Cf. em Marx: "A moral, a religião, a metafísica e qualquer outra ideologia, bem como as formas de consciência a elas correspondentes, são privadas, aqui, da aparência de autonomia que até então possuíam." (Marx \& Engels, 1958, p. 26/94). Ou: "Quando se consideram tais transformações, convém distinguir sempre a transformação material das condições econômicas de produção (...) e as formas jurídicas, políticas, religiosas, artísticas ou filosóficas, em resumo, as formas ideológicas sob as quais os homens adquirem consciência desse conflito e o levam até o fim." (Marx, 1961, p. 9. Trad. Bras.: Marx, p. 48). Também a fala sobre "formas de pensamento" [Gedankenformen] (Marx, 1962, p. 90. Trad. Bras.: Marx, 2011, p. 211) e "formas (...) de pensamento" [Denkformen] (idem, p. 564. Trad. Bras.: Marx, 2011, p. 748). Nesta tese, apoio-me nas interconexões entre $A$ ideologia alemã e 0 capital, pressupondo assim um modelo de continuidade e precisão da crítica da ideologia. Aqui estou eu de lado de Schnädelbach (1969, p. 88) e Herkommer (2004, p.83) contra Rehmann (2008, p. 39). 
Charles Taylor, como um vocabulário de distinções contrastivas (1975, p.165). Assim, normas linguísticas e conceituais não são autônomas, ideia que poderíamos encontrar no cerne de uma teoria materialista, mas estão em relação expressiva com os campos implícitos e não conceituáveis das distinções. ${ }^{19} \mathrm{Na}$ linguagem, essas distinções da práxis se tornam, se pode dizer, "autoconscientes". ${ }^{20}$ Como escrevem Marx e Engels, a linguagem é "a consciência real, prática, que existe para os outros homens e que, portanto, também existe para mim mesmo" (Marx \& Engels, 1958, p. 30/34).

Encontramos assim nas práticas três elementos: a capacidade prática para a distinção, por parte dos sujeitos; padrões aceitos intersubjetivamente que se sedimentam em sanções e valorações mútuas; e um vocabulário no qual essas distinções podem encontrar expressão.

As distinções constitutivas de uma prática não são, afinal, uma coincidência: devemos esperar, acima de tudo, que reflitam as condições objetivas dadas e a adequação da função social da prática sob essas condições, mesmo que não sejam inteiramente determinadas por meio destas. Ou, como afirmam Marx e Engels: “A consciência [Bewusstsein] não pode jamais ser outra coisa do que o ser consciente [bewusste Sein], e o ser dos homens é o seu processo de vida real" (Marx \& Engels, 1958, p. 26/94)

A consciência conceitualmente estruturada (e assim deve-se entender a afirmação acima, creio eu) é o modo pelo qual tornamos explícitos determinados padrões internos de ação que estão implícitos em nossa vida social - mesmo quando não acompanhados do pensamento consciente. Ou, para afirmar de forma mais radical, toda consciência "explícita", ou seja, conceitualmente operante, presume sempre uma normatividade implícita que pode conferir a ela uma expressão, com maior ou menor êxito. ${ }^{21}$

O passo decisivo de uma teoria-prática para a tese de que as ideias são expressão das relações materiais é o seguinte: nas práticas sociais há uma relação expressiva entre, as formas das crenças dos indivíduos, de um lado - como por exemplo: “ a ação de x foi corajosa" - e, de outro, as formas práticas da coordenação da ação. As formas das asserções possibilitadas por meio da práxis se baseiam em distinções que são possíveis e significativas apenas no contexto da práxis (Taylor, 1975, pp. 180183). A relação expressiva que existe nesses casos não é entre o conteúdo da crença

19 Bourdieu também poderia, é claro, ser apontado como testemunha-chave para esta suposição mesmo se não aceitasse os passos adicionais deste argumento.

20 "A linguagem da vida real" [Sprache des wirklichen Lebens]. (Marx \& Engels, 1958, p. 26/93)

21 Como pode se reconhecer sem dificuldade, este modelo se apoia na teoria de uma pragmática normativa (Brandom, 2000). Se atribui corretamente a Brandom ter conduzido a filosofia analítica da linguagem de sua fase Kantiana para sua fase Hegeliana (Rorty, 2000). Uma vez que Brandom assume que as práticas normativas - que encontram sua expressão na linguagem - são práticas em que os indivíduos impõem livremente normas de obrigação e autoridade inferencial a si próprios sem considerar as possibilidades em que as normas correspondentes dependem da coerção da reprodução material e das formas reprodução organizadas pela dominação, ele não está, evidentemente, se comprometendo com o materialismo no sentido de Marx. 
e a práxis (as práticas nas quais vivemos não determinam qual posição tomar por verdadeira), mas entre práxis e forma: as distinções práticas fundamentam as formas conceituais que sempre usamos ao configurar estados de intencionalidade. 0 conteúdo inferencial de conceitos isolados pode ser compreendido no quadro de normas já institucionalizadas pelas práticas. A possibilidade de uma crença correspondente, ou seja, sua forma, é a expressão das distinções institucionalizadas.

Isso permite uma reformulação expressivista da tese da materialidade:

(Mexp): Formas de pensamento expressam exatamente a realidade quando elas são expressões de distinções práticas que, por sua vez, apenas podem ser compreendidas se conectadas a um vocabulário contrastivo - ligado à práxis material - adequado.

No entanto, essa definição da materialidade das formas de pensamento não é ainda uma definição da ideologia. Na Ideologia alemã, Marx e Engels distinguem com clareza duas formas de expressão das relações práticas nas ideias: eles chamam a primeira forma de "consciência" [Bewußtsein]. Essa relação expressiva entra em cena assim que uma forma de produção caracterizada pela divisão "natural” [naturwüchsiger] do trabalho se estabelece (Marx \& Engels, 1958, p. 31/35). A ideologia, por outro lado, surge apenas quando não só ocorre a divisão do trabalho, mas aparece também uma divisão entre "trabalho material e [trabalho] intelectual" (Idem, ibidem). Neste ponto "a consciência pode realmente imaginar ser outra coisa diferente da consciência da práxis existente” (Idem, ibidem). Assim, as ideologias não são dadas apenas pelo fato de que as formas sociais de intercâmbio, especialmente as formas de divisão do trabalho, tomam uma expressão intelectual, mas ocorrem tão somente quando esta expressão, em razão da separação entre produção intelectual e produção corporal, pode ser mal compreendida como uma realidade independente (Hindrichs, 2010; Eagleton, 2000; Schnädelbach, 1969, p. 88) e torna-se autônoma (Marx \& Engels, 1958, p. 540/37). A forma de consciência da ideologia está assim ligada a determinadas relações sociais historicamente desenvolvidas (Eagleton, 2000, p. 89).

Quais critérios para identificar ideologias emergem dessa disposição? Para compreender quando a expressão de uma relação material se torna ideológica precisamos agora transferir a ideia já mencionada de falsas crenças de segunda ordem para o nível das formas práticas. Práticas podem não apenas lidar com objetos, mas também com si mesmas, e tomar suas formas e distinções como objetos. Ou seja, elas podem se tornar reflexivas ${ }^{22}$. Em algumas práticas, classificamos reflexivamente certas

22 Cf. a este respeito Leist (1987, p. 65), que reconhece corretamente o problema quando assume que Marx quer substituir, por meio do materialismo, o conceito do Hegel de espírito. A repreensão de Leist de que a substituição do conceito de espírito pelo conceito de trabalho falha porque no trabalho a ideia de "autorreferência" deve ser explicada ou novamente pelo nível da reflexividade 
distinções - a distinção entre científico e não-científico, entre corajoso e covarde, entre comportamento agradável e comportamento baixo - como uma distinção ligada a uma prática concreta e seus objetivos ou como uma distinção objetivamente dada. Se as ideologias refletem ou expressam corretamente uma forma da práxis, mas o mesmo tempo se consideram erroneamente como independentes, isso apenas pode significar que essa prática contém determinadas distinções com as quais ela classifica as distinções contrastivas (remanescentes) ou como autônomas ou como ligadas à práxis. Assim, o erro deve estar, de fato, do lado da práxis. Práticas ideológicas são práticas que tratam inadequadamente suas próprias distinções contrastantes como atemporais, gerais e objetivas, ou seja, que incorrem em um erro de segunda ordem. ${ }^{23}$

Com isso chegamos a um primeiro conceito de ideologia que, se ainda não cobre todo o campo do ideológico, capta em parte o que foi descrito por Marx e Engels na Ideologia Alemã:

(I1): Ideologia (no primeiro sentido em que o conceito pode ser usado), são formas conceituais que expressam as distinções de uma prática que é, nesse sentido, ideológica, ou seja, que classifica a si mesma como inacessível. ${ }^{24}$

Sob essa definição cabem todas as categorias que se apresentam como objetivas, naturais ou indispensáveis com que abordamos o social (em Marx, "valor", na pedagogia, “inteligência”, mas também "etnia” e etc.) e que, com isso, tornam sua vinculação a interesses, fins e privilégios inacessível. O que é falso nas ideologias, neste primeiro sentido, não é, em primeiro lugar, no que as pessoas acreditam o conteúdo de suas crenças não precisa de modo algum ser falso -, mas a forma com a qual lidam com as distinções nas quais baseiam suas crenças. Mas o que quer dizer exatamente classificar uma distinção como distinção ligada a práxis? Quer dizer, entre outras coisas, estar disponível a modificar a distinção quando ela deixar de servir os objetivos almejados pela práxis. Assim respondeu Oscar Wilde, por exemplo, à pergunta se suas peças teatrais seriam blasfemas, ao dizer que a palavra blasfêmia não pertencia a seu vocabulário (Black, Conolly \& Flint, 2006,

consciente ou através do mero conceito metafórico de retificação, é, no entanto, errada: não é preciso, de modo algum, entender o trabalho como produção individual, mas pode-se entendê-lo como uma prática social normativamente regulada, cooperativa e, ao mesmo tempo, normativaconstitutiva (a própria visão de Marx assim o expõe, nem sempre de modo muito claro). Assim, a ideia de autorreferência já não é difícil de explicar, porque as regras sociais normativas do trabalho são também um trabalho que pode ser regulado socialmente por normas.

23 A distinção de Leist entre um déficit prático e um erro de segunda ordem perde seu ponto (1987, p. 67).

24 As ideologias têm, portanto, algo a ver com ideias, na medida em que a ideologia é a expressão conceitual de uma prática e não um agir sem conceito. Isto não significa, no entanto, que uma ideologia deva negar a afirmação de que a ideologia (no sentido de inacessibilidade ideológica) pode ocorrer em formas físicas e objetivas. 
p.727); deste modo, ele tratou a distinção entre discurso blasfemo e não blasfemo como uma distinção não objetiva, uma distinção que tinha uma finalidade em uma práxis de juízo determinada, cuja orientação implícita, no entanto, ele rejeitava de modo que ele considerou correto abandonar de completo a distinção que estava ligada a essa orientação e que, para além disso, não tinha justificativa intrínseca. Pode-se, portanto, lidar com uma distinção como distinção constituída pela prática, recusando-se a fazê-la, questionando-a ou violando deliberadamente suas regras.

Não se trata necessariamente, na atuação das distinções presentes de uma forma ou de outra nas práticas, de classificações explícitas, e também não se trata necessariamente de juízos estruturados de modo explícito, conceitual ou linguístico. Muitas práticas, no entanto, oferecem possibilidades internas, efetivamente estruturais, para lidar com suas distinções constitutivas como distinções praticamente constituídas, pois possuem regras que determinam como fazê-lo; ou seja, estabelecem como colocar uma distinção em questão sem ter que considerar o comportamento correspondente no âmbito da práxis como irracional ou incompreensível. Exemplos disso são os discursos filosóficos, algumas tradições religiosas ou processos democráticos; mas também a práxis comum de associações ou comunidades instrumentalmente cooperativas pode ser estruturada de modo que as distinções constitutivas dessas práxis possam se tornar objeto de atuação comum de acordo com suas próprias regras.

Se, em uma práxis, as classificações explícitas dessa prática não se converterem em objeto de ações, isto pode ocorrer por razões contingentes ou sistemáticas. As razões da contingência podem indicar ou que os participantes não estão motivados a questionar suas próprias regras em relação aos objetivos da práxis, ou que não estão cientes de que podem. Isso não se trata ainda de ideologia no sentido mais restrito. "Ideologia" não deve significar o domínio de um estado de infelicidade, mas uma forma pela qual as pessoas são sistematicamente dominadas pelos seus próprios produtos. Isso significa que temos de utilizar esse termo para nos referirmos a práticas guiadas por regras em que as distinções não podem ser tratadas como distinções praticamente constituídas por razões estruturais. Devem, portanto, ser práticas em que existam normas socialmente institucionalizadas e aplicadas que não permitam que as classificações que são constitutivas para a práxis sejam tratadas como vinculadas à práxis. ${ }^{25}$

No âmbito de determinadas transações de troca direta, socialmente institucionalizadas, por exemplo, as regras constitutivas do mercado não podem ser negociadas. No âmbito da administração burocrática, o significado das suas distinções

25 A este respeito, a ideologia é estruturalmente idêntica à reificação (Stahl, 2011; 2012). Mas enquanto a reificação diz respeito a uma inacessibilidade da relação das pessoas com o mundo, o termo "ideologia", neste primeiro sentido, refere-se à expressão intelectual de tal relação com o mundo. Assim, as ideologias refletem sempre a práxis reificada; nem todas as práxis reificadas, no entanto, andam de mãos dadas com uma ideologia neste sentido (ou mesmo uma ideologia no segundo sentido discutido abaixo). 
fundamentais não pode ser discutido. Tais práticas, que não permitem que a natureza prática das distinções que as regulam seja tratada como natureza prática, preenchem uma condição necessária para serem consideradas como ideologia, porque nelas as formas de pensamento incorporadas por meio da materialidade são tratadas como formas independentes de pensamento. 0 modo como uma práxis "prescreve" algo não deve ser entendido em um sentido metafisico excêntrico, como se a própria práxis pudesse estabelecer regras. Como escreve Wittgenstein em um contexto semelhante, as leis em questão aqui são as leis humanas, as regras aplicadas pelos seres humanos, e as formas de humanas de dominação (Wittgenstein, 199, p. 80). A dominação ideológica é uma dominação da determinação formal de uma práxis da qual os homens não são vítimas relutantes, mas de uma práxis imposta, pelo contrário, pelos próprios homens. As regras não aplicam a si mesmas e as regras não constituem sujeitos a partir de si próprias, elas devem, antes de mais nada, serem sempre aplicadas pelas pessoas - e como uma regra nunca esgota a sua aplicação, a questão da aplicação correta pode sempre ser disputada. ${ }^{26}$ É claro que existem circunstâncias sociais e históricas em que estas lutas assumem diferentes formas e tornam mais ou menos provável que certas regras possam ser aplicadas. Regras que não permitem que pessoas tratem as normas como normas vinculadas à práxis são plausíveis, em especial se as regras dessa práxis puderem ser estabelecidas por alguns de seus participantes a partir de uma posição privilegiada; a ideologia, portanto, às vezes deixa-se explicar a partir de sua funcionalidade para aqueles que realizam o "trabalho intelectual", ou seja, que planejam e estabelecem regras e interpretam a normas. Tal separação resulta de uma separação entre planejamento e execução, mas também tende a ser natural, se o cumprimento das normas e a reflexão sobre as normas são reservados a espaços e momentos separados (como debates, por exemplo) (Stahl, 2012). Por conseguinte, as ideologias implicam frequentemente a imposição de interesses. Acredito, no entanto, que a ideia de que as ideologias são principalmente a expressão de interesses, o que Marx às vezes sugere, não toca o núcleo do ideológico: ${ }^{27}$ pois isto é, em primeiro lugar, incompatível com a ideia de que as ideologias são a expressão de formas práticas de intercâmbio; e, em segundo lugar, isso se comprova empiricamente em apenas alguns casos - nem ideologias religiosas e nem racistas são sempre a expressão dos interesses daqueles que são favorecidos por elas.

Com isso, pode-se reunir os elementos para uma definição expressivista do ideológico: um fenômeno cognitivo é precisamente ideológico se só puder ser reconstruído em um vocabulário que faça distinções constitutivas explícitas de uma práxis cujas regras não permitem que elas sejam tratadas como distinções

26 Sobre a desconsideração do aspecto da luta nas teorias práticas ver por exemplo Giddens (93, p. 59).

27 Por exemplo, com o modelo da falsa exposição dos interesses de uma classe como interesse geral. Ver Marx e Engels (1958) e também Rosen (1996). 
praticamente constituídas.

Para além do até aqui discutido primeiro sentido expressivo do ideológico (ideológico é o que expressa as distinções de uma prática ideológica), existe, no entanto, uma segunda forma de utiliza-lo:

(I2): Chamamos de ideológicas não apenas crenças e declarações formadas utilizando-se de distinções que estão sob o controle de regras ideológicas de segunda ordem, mas também (no segundo sentido) teorias que legitimam essas regras.

Este é outro modo do uso da palavra "ideológico" na crítica de Marx e Engels aos jovens hegelianos: a teoria dos jovens hegelianos não é apenas uma expressão apropriada de uma falsa práxis, mas também uma teoria sobre conceitos, sobre o intelecto, sobre a relação entre homem e práxis material que expressa e legitima a aceitação das regras de segunda ordem que ocorrem nessa práxis. As ideologias, neste segundo sentido, são assim legitimação filosófica e religiosa de formas de expressão da aceitação do fato de que a nós não é permitido determinar conceitos e juízos frente aos objetivos de nossa práxis. ${ }^{28}$ Mesmo que este segundo significado do conceito de ideologia pressuponha o primeiro, ambos são indispensáveis para compreender a crítica de Marx à naturalização e desistoricização de certas formas de consciência ligadas à práxis, por um lado, e a sua crítica à camuflagem ideológica da reificação da relação do homem com o mundo por meio de teorias explícitas, por outro.

\section{VI - O que é falso na ideologia?}

A definição de ideologia feita até agora baseia-se na ideia de que as ideologias são expressão de relações materiais que já não podem ser entendidas como expressão. Mas o que exatamente é falso em determinada ideologia (ou seja, uma ideologia no primeiro sentido)? Como mostra o exemplo do fetichismo do valor, enquanto a ideologia favorece as crenças cognitivamente falsas (ou seja, não verdadeiras) de segunda ordem, a ciência pode superar essas falsas crenças sem que a natureza "ideológica” da práxis a faça perder seu sentido. Mesmo as ideologias racistas, por exemplo, não podem ser definidas como ideologias porque são empiricamente falsas, embora as crenças falsas de primeira e segunda ordem lhes pertençam necessariamente. Pelo

28 Nesse sentido, pode-se também compreender a definição de Althusser de que a ideologia representa a relação "imaginária" dos indivíduos com suas condições de existência (com as práticas materiais) (Althusser, 2010, p. 75); cf. também "Não são suas condições reais de existência [...] que as 'pessoas' 'representam' na ideologia, mas é sobretudo sua relação com essas condições de existência que é representada" (idem, p. 77). No entanto, deve-se enfatizar que essa relação já deve ser ideológica para ser representada ideologicamente. Se não se faz esta distinção entre o ideológico e o não-ideológico no primeiro nível, então também não se pode fazê-lo no segundo nível, e se entra na noite em que "todos os gatos são pardos", e cada representação da relação indivíduo-práxis é uma ideologia. 
contrário, são a expressão fundamental de uma práxis social de distinções patológicas que, pela sua naturalização constitutiva, não permite questionar a sua adequação. A falsidade específica da ideologia deve, portanto, residir nestas características, que não podem ser reduzidas a sua inverdade.

A fim de esclarecer a questão da natureza da falsidade das ideologias deve-se primeiro analisar porque esta caracterização das ideologias - expressões intelectuais de práticas que não permitem que suas distinções constitutivas sejam tratadas como distinções praticamente constituídas - apresentam apenas uma condição necessária, mas não suficiente para sua falsidade. ${ }^{29}$ Há inúmeras práticas às quais isso se aplica que no entanto não são ideologicamente falsas: as regras do xadrez, por exemplo, não preveem um procedimento em que a distinção entre jogadas “corretas" e “incorretas" possa ser questionada no âmbito do próprio xadrez. No entanto, isso não justifica qualquer crítica às regras explícitas do xadrez como ideologia. No xadrez, a falta dessa possibilidade não representa uma restrição problemática, porque o xadrez não tem uma demanda interna por essa transparência. As práticas ideológicas, pelo contrário, estão erradas porque violam as demandas por transparência que fazem parte das normas dessas práticas (Jaeggi, 2009, pp. 285-287). Por essa razão, apenas as formas expressivas de práticas que são acompanhadas por uma demanda interna, não opcional, por transparência podem ser ideológicas. Ao contrário do xadrez, a economia de mercado, a divisão capitalista do trabalho ou a burocracia não são concebíveis sem a sua própria demanda em proporcionar as condições para que as pessoas possam, com elas, viver livremente as suas vidas. Esta demanda está incrustrada em suas distinções fundamentais entre contratos livres a partir da escolha racional e coerção, entre reivindicações legais legítimas e ilegítimas. Aquele que joga xadrez para ser livre entendeu algo errado; aquele que participa na economia de mercado acreditando ser livre, foi presa de uma ideologia. A diferença entre os dois casos não é trivial.

As ideologias são, portanto, fenômenos cognitivos que só podem ser reconstruídos em um vocabulário que é constitutivo para uma práxis que, por sua vez, se associa a uma demanda constitutiva de seus participantes por transparência e autonomia e que, no entanto, frustra sistematicamente essa demanda de modo que suas distinções constitutivas não podem ser tematizadas adequadamente. A crítica da ideologia pode, portanto, criticar a violação dessa demanda como algo falso, pois se trata de uma demanda institucionalizada pela própria práxis. ${ }^{30}$

Tematização adequada não quer dizer tematização permanente e transparência total, o que iria sobrecarregar qualquer práxis. Onde se localiza a fronteira entre o adequado e o inadequado é antes uma questão política, porque depende que os

29 Cf. aqui a discussão reveladora da "normatividade de segunda ordem" da crítica da ideologia em Jaeggi (2009, pp. 281-283)

30 É, portanto, uma forma de crítica imanente (cf. Stahl, 2013; Jaeggi, 2009, pp. 285-287). 
questionamentos práticos se tornem politicamente relevantes. Como diz Marx, as formas ideológicas são as formas nas quais as pessoas travam suas lutas (Marx, 1961, p. 9, Trad. Bras.: p. 48), pois uma parte dessas lutas exige sempre a possibilidade de questionar e mudar certas distinções institucionalizadas. Uma ideologia não é, portanto, falsa supra-historicamente, mas apenas na medida em que constitui um obstáculo a uma necessidade prática de transparência.

Embora seja relativamente claro que as teorias que legitimam a ideologia no segundo sentido sejam sempre falsas, ainda não está claro se a falsidade das ideologias no primeiro sentido é uma falsidade cognitiva. Obviamente, a norma violada por tais ideologias (ou pelas práticas autobloqueadas expressas em ideologia) não é uma norma epistêmica, mas uma norma prática. Esta norma prática, no entanto, tem implicações no campo cognitivo, na medida em que as práticas ideológicas são práticas de distinção subjacentes às práticas do juízo: Se alguém em uma práxis ideológica faz uma classificação na forma de um juízo, então esse juízo é ideológico porque é tanto verdadeiro quanto falso. ${ }^{31}$ É verdadeiro porque é correto de acordo com as regras da práxis (se for o caso), mas ainda é falso em um sentido indireto. A pessoa que emite o seu juízo na forma desta classificação, de acordo com as regras desta práxis, deve também comprometer-se com uma falsa objetividade de julgamento, uma falsa convicção de segunda ordem, porque a práxis a que pertence a classificação prescreve um comportamento relativo a ela mesma que só pode ser justificado por referência a uma determinada falsa convicção.

Isto significa que os julgamentos em práticas ideológicas não são moralmente falsos. Eles são cognitivamente falsos porque expressam distinções práticas cuja legitimidade só poderia ser justificada por crenças falsas de segunda ordem. Nada podemos fazer além de encontrar nossas crenças no vocabulário de certas distinções ao mesmo tempo em que, temos que nos comprometer, por vezes, com falsas naturalizações. 0 que está em jogo é um imperativo social que não resulta de uma compulsão epistêmica ou lógica autossuficiente, mas da formação de nossas distinções em nossa prática social. O problema da ideologia é, portanto, um problema político e só pode ser resolvido como um problema político. A solução para este problema político, no entanto, não é apenas uma possibilidade para seres com interesses práticos, mas também para nós, como seres racionais, que estamos no lugar de poder reconhecer corretamente tanto nós mesmos como os frutos de nossa própria produção.

\section{Referências}

Althusser, L. (1972). Das Kapital lesen. Hamburg: Rowohlt Taschenbuch Verlag.

Althusser, L. (2010). Ideologie und ideologische Staatsapparate. Hamburg: VSA Verlag.

31 Sobre a interconexão entre verdadeiro e falso a partir de outra perspectiva, cf. Jaeggi (2009, pp. 272-277). 
Black, J.; Conolly, L.; Flint, K. (orgs.). (2006). The Broadview Anthology of British Literature: Volume 5: The Victorian Era. Ontario: Broadview.

Brandom, R. (2000). Expressive Vernunft. Begründung, Repräsentation und diskursive Festlegung. Frankfurt am Main: Suhrkamp.

Cohen, G. A. (2000). Karl Marx's Theory of History. A Defence. Princeton: Princeton University Press.

Eagleton, T. (2000). Ideologie. Eine Einführung. Stuttgart: Metzler Verlag.

Elster, J. (1985). Making Sense of Marx. Cambridge: Cambridge University Press.

Elster, J. (1994). "Functional Explanation: In Social Science”. In: Martin, M.; McIntyre, L. (orgs.). Readings in the Philosophy of the Social Sciences. Cambridge: MIT.

Foucault, M. (1978). Dispositive der Macht. Über Sexualität, Wissen und Wahrheit. Berlin: Merve Verlag.

Geuss, R. (1983). Die idee einer kritischen Theorie. Königstein: Hain bei Athenäum.

Giddens, A. (1993). New Rules of Sociological Method. Stanford: Polity Press.

Habermas, J. (1963). „Zur philosophischen Diskussion um Marx und den Marxismus“. In: Theorie und Praxis. Neuwied: Luchterhand.

Herkommer, S. (2004). Metamorphosen der Ideologie. Zur Analyse des Neoliberalismus durch Pierre Bourdieu und aus marxistischer Perspektiv. Hamburg: VSA Verlag.

Iorio, M. (2003). Karl Marx - Geschichte, Gesellschaft, Politik. Eine Einund Weiterführung. Berlin: De Gruyter

Jaeggi, R. (2009). "Was ist Ideologiekritik". In: Jaeggi, R.; Wesche, T. (Hg.) Was ist Kritik, Frankfurt am Main: Suhrkamp.

Leist, A. (1986). „Schwierigkeiten mit der Ideologiekritik“. In: Angehrn, E.; Lohmann, G. (orgs.). Ethik und Marx. Königstein: Hain bei Athenäum.

Engels, F \& Marx, K. (1958). Die deutsche Ideologie, in: Werke, Band 3. Berlin: DietzVerlag. [Trad. Bras.: Engels, F \& Marx, K. (2007). A ideologia alemã. São Paulo: Boitempo].

Marx, K. (1961). Zur Kritik der politischen Ökonomie. In: Werke, Band 13. Berlin: Dietz-Verlag. [Trad. Bras.: Marx, K. (2008) Contribuição à crítica da economia política. São Paulo: Expressão popular].

Marx, K. (1962). Das Kapital. In: Werke, Band 23. Berlin: Dietz-Verlag. [Trad. Bras.: Marx, K. (2011). O Capital. São Paulo: Boitempo].

Marx, K. (1976). Zur Kritik der Hegelschen Rechtsphilosophie. Kritik des Hegelschen Staatsrechts. In: Werke, Band 1. Berlin: Dietz-Verlag. [Trad. Bras.: Marx, K. (2010) Crítica da filosofia do direito de Hegel. São Paulo: Boitempo].

Rehmann, J. (2008). Einführung in die Ideologietheorie. Hamburg: Argument.

Resch, P. (1992). Althusser and the Renewal of Marxist Social Theory. Berkeley: University of California Press.

Rorty, R. (1992). We Anti-Representationalists. Radical Philosophy, 60, pp.40-42. 
Rorty, R. (1993). Feminism, Ideology, and Deconstruction: A Pragmatist View. Hypatia, 8(2), pp.96-103.

Rorty, R. (2000). „Robert Brandom über soziale Praktiken und Repräsentationen“. In: Wahrheit und Fortschritt. Frankfurt a. M.: Suhrkamp.

Rosen, M. (1996). On Voluntary Servitude. False Consciousness and the Theory of Ideology. Cambridge (MA): Harvard University Press.

Schnädelbach, H. (1969). „Was ist Ideologie?“. Das Argument, 50, pp. 71-92.

Stahl, T. (2010). Eine kritische Theorie sozialer Praktiken. Zu den sozialontologischen Grundlagen immanenter Gesellschaftskritik. Dissertation, Goethe Universität, Frankfurt Am main.

Stahl, T. (2012). „Verdinglichung und Herrschaft. Technikkritik als Kritik sozialer Praxis“. In: Hans Friesen, Christian Lotz, Jakob Meier, Markus Wolf (orgs.). Ding und Verdinglichung, Technik- und Sozialphilosophie nach Heidegger und der Kritischen Theorie. München: Wilhelm Fink.

Taylor, C. (1975). „Interpretation und die Wissenschaften vom Menschen“. In: Erklärung und Interpretation in den Wissenschaften vom Menschen. Frankfurt am Main: Suhrkamp.

Taylor, C. (1998). Hegel. Frankfurt am Main: Suhrkamp.

Therborn, G. (1980). The Ideology of Power and the Power of Ideology. London: Verso. 